\section{NOTES AND CORRESPONDENCE.}

\section{DETERMINATION OF TIN AND ANTIMONY IN SOFT SOLDER.}

The following details for the rapid volumetric determination of tin and antimony in soft solder are adapted from A. H. Low's method. ${ }^{r}$

Antimony.-On a counterpoised watch glass weight exactly 2 grams of filings, which should be fine enough to pass a 30 -mesh sieve. With a quill brush transfer the filings through a stemless funnel into a $300 \mathrm{cc}$. Jena Erlenmeyer flask. Add 5 grams of $\mathrm{KHSO}_{4}$ crystals and Io cc. of sulphuric acid, specific gravity I.8. By means of cork-lined tongs or test tube holder manipulate the flask over a bare Bunsen flame until most of the free acid is expelled and no sulphur remains on the walls of the flask nor in the liquid. Do not attempt to take to dryness. Place the hot flask on a piece of asbestos. The tin is now all a stannic and the antimony all an antimonous salt. When the flask cools sufficiently add $25 \mathrm{cc}$. of cold water and $5 \mathrm{cc}^{2}$ of hydrochloric acid, specific gravity I.2. Manipulate over a free flame for half a minute to complete the solution of the tin and antimony salts and to expel any sulphuric dioxide. Cool the flask under running water. Add roo ce. of cold water and titrate rapidly with $\mathrm{N} / 20$ potassium permanganate. From the volume of the latter required to give the first pink color calculate the per cent. of antimony. Dry to constant weight some highest purity sodium oxalate, made according to Sorensen, and use this to standardize the $N / 20$ potassium permanganate solution.

Tin.-Weigh exactly 0,2 gram of the filings and transfer as before to a $300 \mathrm{cc}$. Jena Erlenmeyer flask. Add $5 \mathrm{cc}$. of $\mathrm{s}_{5}$ per cent. sodium carbonate solution. Add $20 \mathrm{cc}$. of hot water. Add $25 \mathrm{cc}$. of hydrochloric acid, I.2 specific gravity. Add one drop of 5 per cent. antimony chloride solution from a dropping bottle. This solution should be strongly acid with $\mathrm{HCl}$. Close the flask with a I-hole rubber stopper carrying a capillary U-tube of I $\mathrm{mm}$. bore. The short arm of the U-tube should just reach through the stopper while the long arm should almost reach the surface on which the flask stands. Place the flask on a hot plate where it will boil very slowly but not suck air back through the tube. The solder will dissolve in about I 5 minutes, leaving a small black precipitate of antimony. As soon as this occurs and without interrupting the slow boiling bring a test tube of $\mathrm{I} 5$ per cent. sodium carbonate solution under the $\tau$-tube. Carry to the sink and cool the flask under running water, allowing the carbonate solution to suck back into it. When cold add $5 \mathrm{cc}$. of $\mathrm{I}_{5}$ per cent. sodium carbonate solution and $5 \mathrm{cc}$. of cold, fresh starch liquor and titrate immediately with $\mathrm{N} / 20$ iodine solution. From the volume of the latter required to give the first deep blue color calculate the per cent. of tin. Standardize the $\mathrm{N} / 20$ iodine solution by titrating in the same way o.I gram portions of filings made from a stick of Kahlbaum's highest purity tin.

J. Am. Chem. Soc., 29, 66

2 P. H. Walker and H. A. Whitman also use less hydrochloric acid than A. H. Low, ThIS JourNal, 1, 519.
This method can be used to advantage for soft solder containing $a$ to 2 per cent. of antimony, 30 to 60 per cent. of tin, 40 to 70 per cent. of lead and not more than traces of any other metals. Duplicate determinations of tin and antimony can be made in one hour.

J. H. GOODWIS.

\section{THE USE OF ALUNDUM CRUCIBLES IN FATTY ACID DETERMINATIONS.}

Recently the writer has had some opportunities of making separations and determining fatty acids from soaps and soap powders.

These separations were, at first, made by the usual methods, as taking up with beeswax, or upon a balanced filter.

The porous alundum crucibles, manufactured by the Norton Co., were then used as a Gooch crucible, by placing the crucible into a Gooch funnel, using a filtering bottle and a pump for suction.

The method used was by acidifying the soap solution, as usual, with an acid, allowing it to stand for some time, to give the fatty acids enough time to thoroughly coagulate. The solution was then run through this crucible, which was weighed, and the acids remaining in the crucible washed once or twice with cold water. It was then dried and weighed.

The writer finds this method to be very rapid and accurate. When the determinations are completed the fatty acids can be burned out very readily, leaving the crucible as clean as before filtering, and may be used again for a considerable number of determinations.

As the crucible is not acted upon, or contaminating the solutions with any foreign matter, but leaving it in a perfectly clear state, the filtrate passing through may be used for other determinations if so desired.

As this method is found to be more rapid and fully as accurate as the two former methods, also owing to the fact that the crucible can be used for numerous determinations, the writer can say that the use of these crucibles excel any methods, for this separation. H. O. ANDERSON.

\section{DISSOLVING SILICON ALLOYS. \\ Editor Joumal of Industrial and Engineering Chem- istry:}

In working on some silicon alloys recently I found they may be readily decomposed by a mixture of strong hydrofluoric with hydrochloric or sulphuric acid.

The alloys so far tried include samples of 50 per cent. ferro-silicon and one of silico-spiegel ( 2 I per cent. $\mathrm{Si}, 39$ per cent. Mn and 42 per cent. Cr). The sample is placed in a large platinum crucible, conc. hydrofluoric acid added and then hydrochloric or sulphuric as desired. The solution starts at once and is complete in a few minutes at a low heat. The sample does not even have to be finely powdered for I have dissolved ordinary crushed ferro-silicon in pieces as large as Io mesh.

For determination of iron or manganese this method is much more rapid and far simpler than either of the fusion methods. 